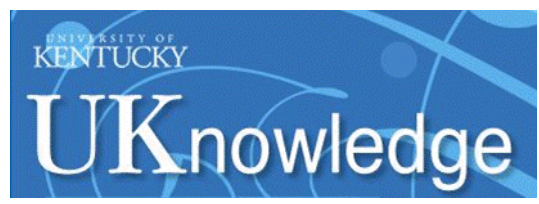

University of Kentucky

UKnowledge

\title{
SHELTER AVAILABILITY, OCCUPANCY, AND RESIDENCY IN SIZE- ASYMMETRIC CONTESTS BETWEEN RUSTY CRAYFISH, ORCONECTES RUSTICUS
}

Nathan M. Klar

University of Kentucky, nmklar2@uky.edu

Right click to open a feedback form in a new tab to let us know how this document benefits you.

\section{Recommended Citation}

Klar, Nathan M., "SHELTER AVAILABILITY, OCCUPANCY, AND RESIDENCY IN SIZE-ASYMMETRIC CONTESTS BETWEEN RUSTY CRAYFISH, ORCONECTES RUSTICUS" (2010). University of Kentucky Master's Theses. 52.

https://uknowledge.uky.edu/gradschool_theses/52

This Thesis is brought to you for free and open access by the Graduate School at UKnowledge. It has been accepted for inclusion in University of Kentucky Master's Theses by an authorized administrator of UKnowledge. For more information, please contact UKnowledge@lsv.uky.edu. 


\section{ABSTRACT OF THESIS}

\section{SHELTER AVAILABILITY, OCCUPANCY, AND RESIDENCY IN SIZE-ASYMMETRIC CONTESTS BETWEEN RUSTY CRAYFISH, ORCONECTES RUSTICUS}

Contest outcomes are usually determined by differences in resource holding potential, the social histories of the combatants, and perceptions of resource value. One understudied aspect of gaining an advantage is the residency effect. Prior occupancy of a particular place can affect the knowledge and motivation of the resident. There could be a tactical advantage in knowing the terrain or an increased willingness to fight to maintain control of a familiar area. In this study we evaluated the importance of shelter residency effects relative to size differences between rusty crayfish (Orconectes rusticus) as potential competitors for access to shelter. The intensity of any residency effects was manipulated by altering the number of shelters in the arena. Our results suggest that any residency effect is very weak in this system, and if present may often be masked by the strong and pervasive influence on contest outcome of the relative body sizes of the contestants. We also found that both shelter number and crayfish size asymmetries had strong, independent effects on levels of aggression. Dominance, but not residency status, was a factor in shelter use.

KEYWORDS: aggression, dominance, resource holding potential (RHP), resource limitation, shelter

Nathan M Klar 


\section{SHELTER AVAILABILITY, OCCUPANCY, AND RESIDENCY IN SIZE-ASYMMETRIC CONTESTS BETWEEN RUSTY CRAYFISH, ORCONECTES RUSTICUS}

\section{By}

Nathan M Klar

Philip H Crowley

Director of Thesis

Brian C Rymond

Director of Graduate Studies

$8 / 27 / 10$

Date 


\section{RULES FOR THE USE OF THESES}

Unpublished theses submitted for the Master's degree and deposited in the University of Kentucky Library are as a rule open for inspection, but are to be used only with due regard to the rights of the authors. Bibliographical references may be noted, but quotations or summaries of parts may be published only with the permission of the author and with the usual scholarly acknowledgements.

Extensive copying or publication of the thesis in whole or in part also requires the consent of the Dean of the Graduate School of the University of Kentucky.

A library that borrows this thesis for use by its patrons is expected to secure the signature of each user.

$\underline{\text { Name }}$

$\underline{\text { Date }}$ 


\section{THESIS}

Nathan M Klar

The Graduate School

University of Kentucky

2010 


\title{
SHELTER AVAILABILITY, OCCUPANCY, AND RESIDENCY IN SIZE-ASYMMETRIC CONTESTS BETWEEN RUSTY CRAYFISH, ORCONECTES RUSTICUS
}

\section{THESIS}

A thesis submitted in partial fulfillment of the requirements for the degree of Master of Science in the College of Arts \& Sciences at the University of Kentucky

\author{
By \\ Nathan M Klar \\ Lexington, Kentucky \\ Director: Dr. Philip H Crowley, Professor of Biology \\ Lexington, Kentucky \\ 2010 \\ Copyright ${ }^{\circledR}$ Nathan M Klar 2010
}




\section{TABLE OF CONTENTS}

\section{Chapter One}

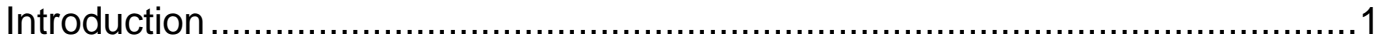

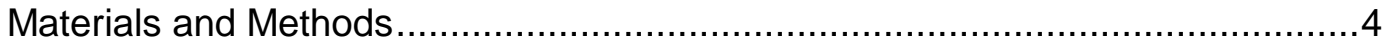

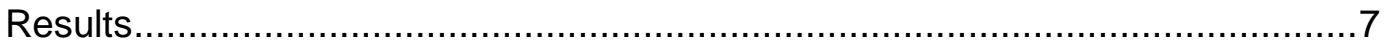

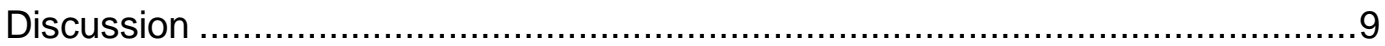

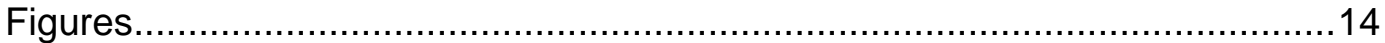

Chapter Two

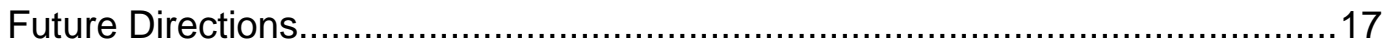

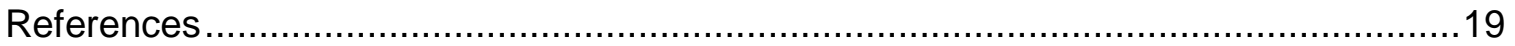

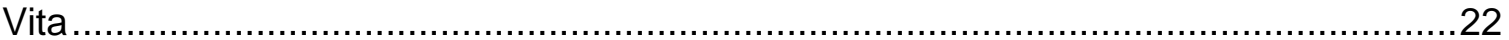


Chapter 1.

Introduction

Aggression is a common behavioral response to conspecifics competing for a limiting resource. If the resource is of enough value to two individuals, physical combat may ensue. Outcomes of such contests are largely determined by differences in resource holding potential (RHP; originally termed "resource holding power" by Parker 1974), which is primarily set by relative size (e.g. Rabeni 1985; Pavey and Fielder 1996) and by past experiences resulting in winner and loser effects (Dugatkin 1997; Hsu and Wolf 1999), or the tendency for winners to keep winning and for losers to keep losing. Other determinants of RHP include age, sex, and physiological state (reviewed in Dugatkin \& Reeve 1998). Because these factors are often correlated with each other and may interact in complex ways unique to a given animal system, it is difficult to generalize about which are most important.

When competing for a spatially explicit resource, or competing for a territory that provides access to resources, the outcome of a contest is often influenced by residency effects (Hack et al. 1997; Rosenberg \& Enquist 1991; Takeuchi 2006). Residency effects are any factors that confer an advantage to the current owner of a resource or territory. Such effects have been explained by diverse mechanisms ranging from physiological to behavioral. A straightforward explanation for observed residency effects in the wild is the greater expected intrinsic abilities of residents (Whiting et al. 2006). A current resident may have acquired its territory via an earlier contest settled by size or strength. This could also give the resident valuable fighting experience and possibly winner effects. Because arbitrarily chosen residents can have higher success in 
controlled experiments without any recent fighting experience (Alcock \& Bailey 1997), there must be mechanisms by which residency itself increases an individual's RHP. Animals that occupy shelters or burrows may be able to use them to gain a tactical edge over an opponent (e.g. Fayed et al. 2008). Also, residents and intruders may value the resource differently. For example, a resident that places a higher value on a territory than an intruder does will be more motivated to fight for the territory and will tend to enjoy greater success in contests (Parker 1974; Leimar \& Enquist 1984; Enquist \& Leimar 1987; Arnott \& Elwood 2008). Residents have the opportunity to place higher values on territories because they have more knowledge of their surroundings than do non-residents. Furthermore, intruders may expect territory holders to be of higher RHP, and intruders may be more likely to yield as a matter of convention (Maynard Smith 1982). This conventional outcome is most likely in animals that lack the ability to evaluate their opponents effectively through other means (Takeuchi 2006) such as vision or olfactory cues.

If there are clear, consistent outcomes in these contests, we say that the dyad has a dominance relationship (Landau 1951). Because establishing dominance can carry high costs in time, energy, and risk of injury, we expect dominance to provide increased access to resources (Wilson 1975). While this may generally be true in the long term, snapshots in time of dominant behavior may suggest otherwise. In a recent study to determine the benefits of social dominance in the rusty crayfish (Orconectes rusticus), dominant individuals were found to occupy shelters significantly less often than subordinate individuals (Fero et al. 2007). In the Fero et al. (2007) analysis (as in the present study) shelters were small, discrete structures that provided a crayfish with some physical isolation from the environment.

There are several circumstances that could account for the counterintuitive result of dominant individuals using a resource less than subordinates. Dominant individuals 
often interact with subordinates to reinforce their status (Gherardi \& Daniels 2003; Gherardi \& Atema 2005). Repeated dominance displays decrease the likelihood of a subordinate attacking in the future and could signal an individual's dominance to bystanders (Dugatkin 2001; Earley \& Dugatkin 2002). Also, shelters are generally static in space and time, often provide direct access to other resources, and are reusable. The property of being reusable allows a dominant individual to utilize this resource at its discretion. When competing for shelter in the absence of predator cues, we might expect already dominant animals to temporarily abandon a shelter to explore the environment or reinforce its status.

In the present study we tested residency effects against size asymmetry effects in the rusty crayfish. While previous studies have simultaneously tested for size and residency effects in other systems (Turner 1994; Jennions \& Backwell 1996; Caballero \& Castro 1999; Morishita et al. 2009), they have not included multiple levels of size asymmetries in which the intruders were larger than the residents by varying degrees. In our study intruders were $0-1 \%$ (hereafter, $0 \%$ ), 4-6\% (5\%), or $14-16 \%(15 \%)$ larger than residents. Our preliminary trials to test size asymmetries in the absence of residency effects suggested that larger crayfish win almost every contest when the size difference is greater than $10 \%$. Similar results have been found in red swamp crayfish (Figler et al. 1995), in which individuals 25\% larger than their opponents always immediately dominated them.

In the present study, we considered these three relative size differences across three levels of shelter in an attempt to manipulate the perceived value of the area inside the test arena and test the strength of any residency effects. Arenas contained zero, one, or two shelters. Very few studies have actually observed aggression over a range of shelter abundance (but see Sale 1972; Martin \& Moore 2007). Instead levels of aggression are often reported for a single level of shelter. We predict that aggression 
will be highest when size-matched individuals are competing for one shelter, and that resident crayfish will dominate intruders of similar size (a $5 \%$ or less size difference). When $15 \%$ larger, we predict the intruders will always dominate and readily evict residents from shelters.

Materials and Methods

Study organism

Rusty crayfish, Orconectes rusticus, are found in lakes, streams, and rivers of all sizes. In streams and rivers they are often found under rocks or around woody debris. In lakes they prefer rooted vegetation and submersed logs (Taylor \& Schuster 2004). The basic ecology of $O$. rusticus was described by Prins (1968). Rusty crayfish became sexually mature in 15 months and females oviposited in the spring at an age of $22-24$ months. Most individuals did not live beyond 2.5 years. The most common food items were detritus and vascular plants.

Rusty crayfish are native to the Ohio River drainage basin, but have garnered much attention in recent decades due to their spread northward. They have been found in about a dozen states with Wisconsin and Michigan sustaining large, widespread populations (Lodge et al. 2000). One long-term study in a Wisconsin lake found that since the introduction of rusty crayfish, there has been a decline in native taxa across multiple trophic levels (Wilson et al. 2004). They are voracious eaters, often directly outcompeting native crayfish while depleting populations of aquatic plants and insects.

Crayfish were obtained from a supplier in Amherst Junction, Wisconsin in September, 2009. Males were immediately isolated in 1-gallon plastic, opaque containers and kept in isolation until they were used in trials. Females were excluded 
from the study to eliminate any sex effects. Water in these containers was changed twice weekly. Crayfish were maintained on a $14 \mathrm{~h}: 10 \mathrm{~h}$ light-dark cycle and fed commercial fish food pellets. Water temperature fluctuated between $20^{\circ} \mathrm{C}$ and $24^{\circ} \mathrm{C}$. Any crayfish discovered to have molted was not used in a trial for at least seven days. Individuals were only used once in this experiment.

\section{Test Arena}

Trials were conducted in opaque plastic containers $(24 \times 36 \mathrm{~cm}$ x $8 \mathrm{~cm}$ water depth) with white gravel to provide a semi-natural substrate while allowing enough color contrast to facilitate viewing of behavioral interactions. Shelters were made by attaching two DVDs at the ends of a $5 \mathrm{~cm}$ length of wood dowel rod and painting the DVDs and dowel dark brown. Shelters were placed in corners of the test arenas by burying one of the DVDs underneath the gravel to provide stability for the canopy. These would not be ideal shelters for crayfish in the wild as they offer little lateral protection; they were chosen for this study to minimize any tactical advantage of ownership (such as would come from a length of PVC pipe with only one or two openings to defend). Trials were recorded using digital camcorders (Sony model No. DCR-SR42 and JVC model No. GZ-MG130U).

\section{Experimental protocol}

To test the effects of relative body size, residency status, and shelter number on dominance and shelter occupancy, agonistic interactions and shelter use were observed in pairs of male crayfish. Resident crayfish were placed in an arena containing zero, one, or two shelters for a period of four hours. An intruder was then added for two hours. Intruders were $0 \%, 5 \%$, or $15 \%$ larger than residents. As in most crayfish 
studies, size was measured as post-orbital carapace length. Because chela size increases allometrically with carapace length in rusty crayfish (Garvey \& Stein 1993), individuals were only removed from the experiment if one or both chelae were disproportionate as a result of injury and regeneration. For each treatment 16 replicates were performed (288 crayfish), the number constrained by the logistics of maintaining a large number of crayfish, each in isolation. Because of this limited sample size, testing for resident dominance as a function of size asymmetry and shelter number was done by pooling one treatment across the other treatment. This produces correlations among these tests, and results should thus be interpreted with caution. All trials were conducted during the latter half of the day as defined by the photoperiod of exposure.

Agonistic behaviors were categorized as either fighting events or aggressive/submissive interactions. We defined a fighting event as an interaction between two individuals in which both are actively engaged in combat, including mutual grasping and pursuit. The fighting event ended when one individual retreated. An aggressive/submissive interaction was defined as an interaction in which at least one crayfish was displaying aggressive behavior and one showed submissive behaviors. This definition encompasses contests, but also includes encounters in which one individual did not actively fight.

\section{Statistical Analysis}

Statistical tests were performed in SYSTAT 12 (Systat Software, Inc.). Fighting events and aggressive/submissive interactions were analyzed using ANOVA with number of shelters and size difference as factors. A repeated measures ANOVA was used for aggressive/submissive interactions, but not for fighting events due to an abundance of zeroes in the time series data. When the main effects were significant, Tukey's HSD 
test was used to test for differences between treatments. Time in shelter for residents and intruders was compared using t tests. Resident and intruder shelter usage were also analyzed separately using repeated measures ANOVAs with size asymmetry and dominance status as factors. To test for an effect of shelter number on the dominance of residents, trial outcomes were pooled by shelter number and compared using the $Z$ test for two proportions. To test for the presence of residency effects across size asymmetries, the proportion of dominant residents was compared to values expected in the absence of any residency effects. Observed proportions were compared to expected values using $\mathrm{G}$ tests.

\section{Results}

\section{Dominance}

When the trial outcomes were pooled by number of shelters, there was no effect of shelter number on the proportion of trials in which the resident emerged as dominant. The larger (non-resident) individual tended to dominate the smaller (resident) when $5 \%$ and $15 \%$ size differences were pooled together and compared against $0 \%(Z=2.48, p=$ 0.01). The difference between $5 \%$ and $15 \%$ was less conclusive $(Z=1.913, p=0.06)$, though the larger (non-resident) individual tended to dominate. At $0 \%$ size difference the proportion of dominant residents (22/48) was not significantly different from one half $(\mathrm{G}=$ 0.17 , d.f. $=1, p=0.68)$. Results from the $5 \%$ trials $(16 / 48)$ also showed no significant difference from one half $(G=2.72$, d.f. $=1, p=0.10)$. Surprisingly, some of the residents that were $15 \%$ smaller than their intruders did become dominant. This proportion (7/48) was significantly greater than zero $(G=8.02$, d.f. $=1$, $p<0.005)$, but less than half $(G=13.33$, d.f. $=1, p<0.001)$. 


\section{Shelter Use}

Time in shelter was only obtained for the 1-shelter trials. Although total time in shelter was not different overall for residents and intruders $(t=-1.43, p=0.16)$, there was a difference in the first hour of the trials $(t=-1.92, p=0.05)$ with residents using shelter for $1042.5 \mathrm{~s} \pm 118.5$ (29\%) and intruders for $1373.4 \mathrm{~s} \pm 125.4$ (38\%)(Fig. 1). There was no difference in the second hour $(t=-0.84, p=0.40$; Fig. 1). For residents, dominance status increased time in shelter (repeated measures ANOVA, $F=4.37, p=0.04$ ), but size difference had no effect $(F=0.59, p=0.56)$ and there was no significant interaction between the two $(F=0.30, p=0.74)$. Time interval was significant $(F=7.79, p=0.008)$ and interacted significantly with dominance $(F=4.48, p=0.04)$, but not with size difference $(F=2.50, p=0.09)$. Residents spent more time in the shelter in the second hour and when they were dominant. Similarly for intruders, dominance status was significant $(F=6.83, p=0.01)$, but size difference was not $(F=0.44, p=0.65)$ and there was no interaction $(F=0.71, p=0.50)$. But time interval was not significant $(F=0.49, p$ $=0.49)$ and did not interact with dominance $(F=0.86, p=0.36)$ or size difference $(F=$ $0.66, p=0.52)$.

\section{Aggression}

The number of fighting events was determined by both shelter number $(F=5.96, p<$ $0.005)$ and size difference $(F=4.47, p=0.01)$ with no significant interaction between the two factors $(F=1.77, p=0.14)$. Tukey's post hoc tests showed that fighting events were more frequent at zero shelters than two $(p<0.005)$ and more at $0 \%$ size difference than $15 \%(p=0.02)$

The number of aggressive/submissive interactions (includes fighting events) was also influenced by shelter number $(F=22.97, p<0.001)$ and size difference $(F=4.00, p$ $=0.02)$ with no significant interaction $(F=0.28, p=0.89)$. Similar to the fighting results, 
aggressive/submissive interactions increased as shelters and size asymmetries

decreased. A repeated measures ANOVA revealed a significant effect of time $(F=1.77$, $p<0.001$; Fig. 2) and no significant interaction with shelter number $(F=0.54, p=0.78)$ or size difference $(F=0.96, p=0.45)$.

An overview of the relationships among variables in this study is presented in Figure 3.

\section{Discussion}

Aggression, measured both as the number of fighting events and the total number of aggressive/submissive interactions, increased as the size difference between opponents and the number of shelters decreased. Increasing aggression with decreasing shelter number is probably caused by two factors. First, as with any other potentially valuable resource, competition will intensify as the amount of the resource decreases and exposure to competitors increases. Also, the nature of shelter as a resource tends to isolate individuals, decreasing the opportunities for interaction. When we analyzed aggression over time, we found the anticipated decline in hostilities with both the number of fights and total aggressive/submissive interactions following similar paths. Given the small size of the arenas, we did not expect total aggressive/submissive interactions to decline as quickly as fighting events. Although dominance may be quickly settled for a given dyad, there is little space for the subordinate to flee from the dominant as it would in a natural setting. Surprisingly, the rate of decline was not affected by the number of shelters or crayfish size asymmetries.

The level of aggression, as determined by the availability of shelters, could have an impact on the fighting success rates of residents. Because more aggressive individuals tend to be favored in many animal contests, it is conceivable that low shelter 
availability could provide an advantage to some of our contestants. Conversely, escalating a fight with a larger individual may lead to more failures than successes (as discussed later). Unfortunately our measure of dominance precludes such an analysis. Dominant status was assessed at the completion of each trial so it is impossible to determine if more aggressive crayfish tended to become dominant or if dominant crayfish were more aggressive to their respective subordinates who lacked a means of escape.

While the impact of size on dominance was strong, the effect of residency status was less clear. When opponents were matched in size, we found no advantage for residents; any effect of residency should have been clear in these trials. In fact, only 22 out of 48 residents were dominant when size-matched to the intruders. On the other hand, 7 of the 48 smaller resident crayfish in the $15 \%$ trials emerged as dominant, despite being smaller. In a pilot study in which crayfish were introduced into neutral arenas, we found that a $15 \%$ size difference prevented smaller individuals from ever winning an interaction (8 observed dyads). The comparison with this earlier result suggests that residency may have effects in some circumstances.

In previous studies examining the relative importance of size asymmetries and residency status, researchers have obtained mixed results. This may result from multiple interacting mechanisms that underlie residency effects. In some systems, residency status has little influence on contest outcome (e.g. Hastings 1989; Edwards \& Dimock 1991). Other studies demonstrate a significant residency effect, but one that is easily overpowered by size effects (e.g. Evans \& Shehadi-Moacdieh 1988). In cases with strong residency effects, smaller residents commonly emerge victorious over larger intruders (Gribbin \& Thompson 1991; Koivula et al. 1993; Alcock \& Bailey 1997). In the present study we found only very weak evidence regarding a residency advantage. 
Greater replication in comparisons of individuals differing in size with the smaller as resident may ultimately reveal a small residency advantage.

Statistical evidence from the present study for a residency effect hinges on the finding that 7 of 48 residents that were $15 \%$ smaller than intruders were nevertheless able to dominate them, while the smaller of two individuals introduced simultaneously into their container dominated in 0 of 8 previous trials. But suppose that $7 / 48$ were the true chance that the smaller is dominant even for simultaneous introduction (i.e. no residency effect). Then the chance that none of the eight smaller individuals would be dominant in pairs introduced simultaneously is $(1-7 / 48)^{8}=0.283$. This probability is not low enough to provide convincing evidence for a statistical difference in outcomes between the two cases.

It should be noted that no shelters were present in the pilot study, but the shelters used in the current study were designed to confer no defensive advantage to the resident from conspecifics. Thus in the absence of a shelter advantage in interactions with other crayfish and the absence of any predator cues, the value of shelter residency may have been low. Thus the larger crayfish probably had little motivation to fight with the smaller ones. The smaller crayfish, acting with the increased tenacity often associated with resource holders (e.g. Tricarico \& Gherardi 2010), may have been more aggressive at the onset of a confrontation. This would suggest that the residency advantage in our experiment was limited to trials in which there was minimal escalation by the larger individual. The more both individuals are intent on engaging in fighting, the more often the winner is likely to be determined by differences in RHP (via intrinsic abilities such as size).

Dominant status was assigned to the individuals that consistently won fighting events or displayed dominant behaviors while the opponent was submissive. For most of the trials, there was no shift in dominance behaviors. Once an individual was 
dominant, it tended to stay dominant for the remainder of the trial. But there were 13 trials in which the two crayfish switched dominance roles. This always occurred early (first 30 minutes) and was usually a smaller resident that held on for some time before conceding to the larger intruder (9 out of 13).

There are several possible explanations for this pattern. A similar pattern was seen in the dragonfly Perithemis tenera (Switzer 2004), for which the advantage to being a resident dragonfly only held until fights were escalated. In this case the cause of the residency advantage could be differences in perceived value of the territory, or perhaps intruders were more likely to yield as an arbitrary means of settling the dispute because residents are more likely to have RHP. Another possibility in the current study is that residents were willing to fight harder and longer for a resource already in their possession, but were eventually overcome by the size advantage of the intruders. This explanation is partially supported by the trials in which the eventual subordinate resident won early fights. In the few trials in which the eventual subordinate resident was initially dominant through displays alone, an asymmetry in perceived value of the shelter seems the more likely explanation.

Access to shelters was primarily determined by dominance. Contrary to Fero et al.'s findings (2007), dominant crayfish in our study spent more time in shelters than subordinates. This difference may be related to the smaller size of our arenas and the use of dyads instead of groups. Dominant individuals had less area to explore and fewer subordinates with which to reinforce status. When observation time was not subdivided into sequential intervals in the analysis, neither residency status nor size was a significant factor in determining total time spent in shelter. A power analysis revealed that 185 dyads would be needed to obtain statistical significance with our effect size for residency status. When the two hours were analyzed separately, residents and intruders did not differ in shelter use in the second hour, but intruders spent significantly 
more time in shelter during the first hour. This is counter to the traditional idea that crayfish placed in novel environments will spend large amounts of time exploring the new environment (Li \& Cooper 2001). It seems possible that the intruders, upon being thrust into unknown surroundings, would seek immediate shelter. In the absence of predator cues, these intruders could quickly shift their attention to exploration. This does not, however, fit with the trend of increased shelter usage during the second hour.

The results of this study suggest that there could be a weak residency advantage in this system, but any such advantage would be easily overpowered by size asymmetries. But are there factors that could mitigate the effect of size in a natural setting? This probably hinges on the local movements of individuals within a population. If a group of individuals is relatively static and rarely incorporates new members, then it seems unlikely that interactions between individuals of drastically different RHP would be common. Recent theoretical work has demonstrated that groups of individuals will spatially sort by rank (Hemelrijk 2000). If, however, it is a large group of individuals or the group membership changes frequently, conflicts between individuals of very different size classes may be common. Future work should focus on naturally occurring interactions to see if such asymmetrical contests occur in the field and, if they do, to determine the relative strength of a size advantage. Future studies should also explore the effects of residency time and shelter defensibility on the residency advantage in crayfish. It seems likely that increasing the time in which the resident is alone in the arena will increase the strength of most kinds of residency effects. Also, different types of shelter could have numerous impacts for residents. Crayfish should be more likely to defend shelters that they consider of higher value. In addition to this motivational change, some shelter geometries are naturally more suited to intruder defense. 
Figure 1. Time spent in shelter per hour by resident and intruder crayfish in the oneshelter trials. Error bars are standard error.

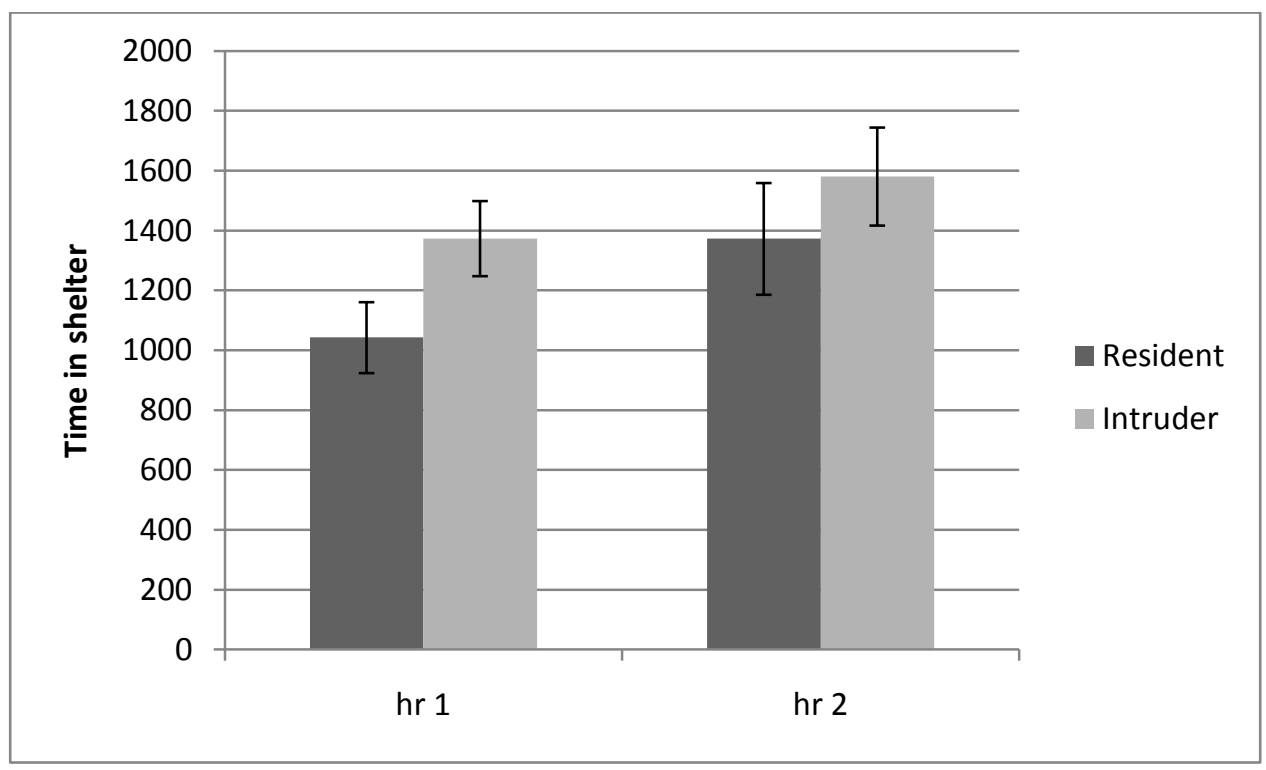


Figure 2. Aggressive interactions in 30-minute blocks for A) \# of shelters and B) \% size difference. Error bars are standard error. Dashed lines represent overall means adjusted for 30-minute intervals.

A)

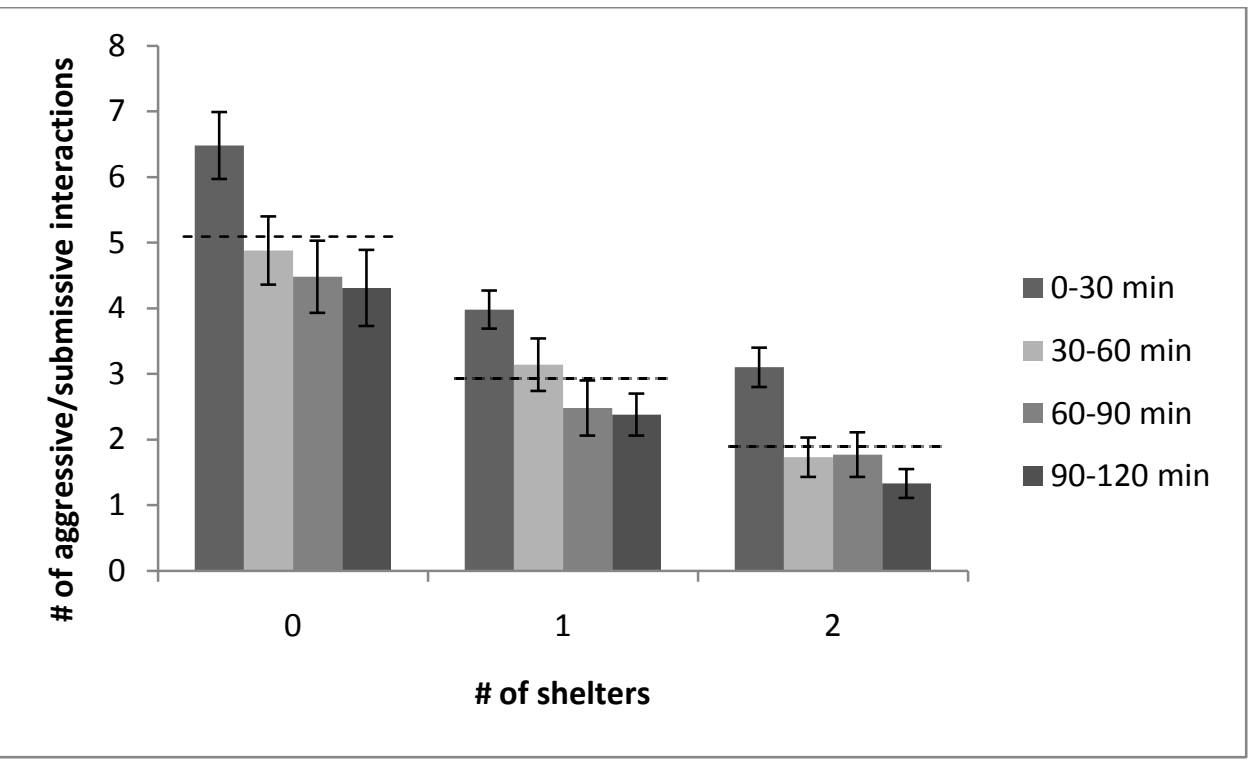

B)

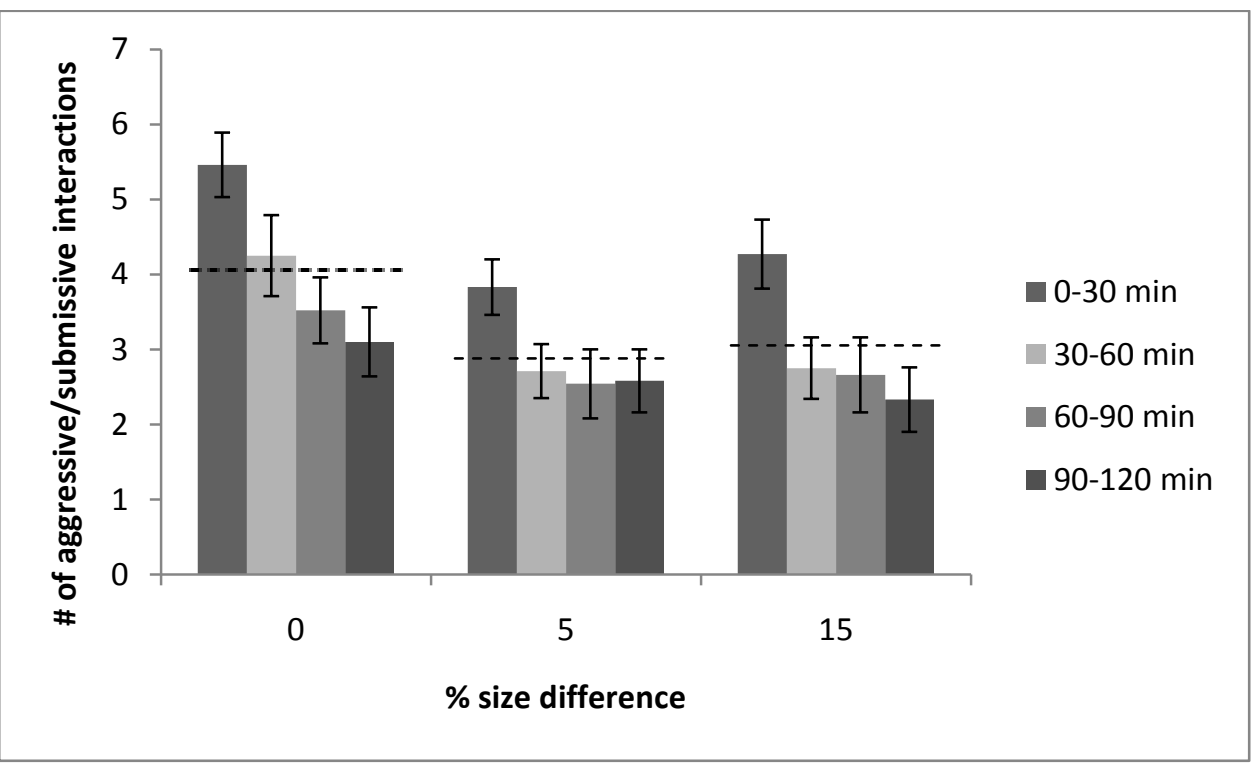


Figure 3. Relationships among variables in the analysis. Double-line boxes enclose the manipulated variables; single-line boxes contain the response variables; arrows between them illustrate detected effects of indicated sign, with the bold arrow emphasizing the strongest relationship. The dotted-line box represents access to food, mates, and protection from predators---variables not included in the present analysis but proposed for future work; hypothetical linkages to these variables are indicated by dotted arrows and associated signs. Arrows intercepting another arrow suggest interacting effects.

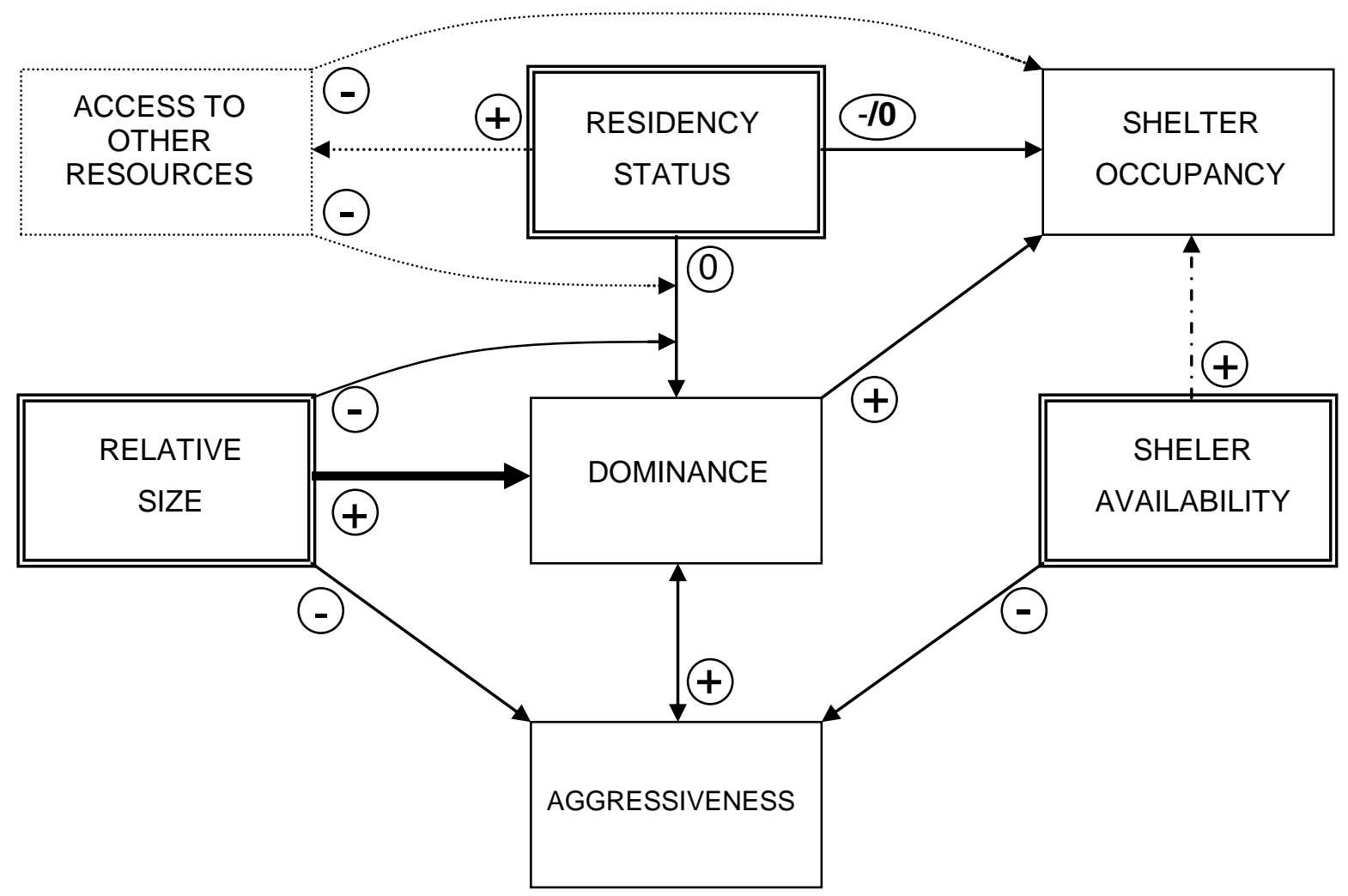


Chapter 2. Future Directions

The present study provides a wide range of opportunities for related future work. Some of these are simply alterations of the current experimental design to better simulate natural conditions, such as larger arena size and a longer residency period. In the present study, the entire arena is smaller than some natural territories, and subordinates had no means of retreat, perhaps resulting in more status reinforcement and less shelter occupancy by dominants than in nature. Moreover, the 4-hour initial residency period with only the resident present in the arena may have been insufficient to produce a strong residency effect; extending this interval before introducing the intruder might keep a residency response from being too weak to detect.

Another way to mimic natural settings more realistically is to add predator cues. For crayfish, this could be done by adding water that previously housed a natural predator of crayfish or water that contained crushed crayfish pieces to simulate predation. Adding these cues would most likely increase the motivation to acquire and remain in shelters. This may limit the time dominant individuals spend chasing subordinates around the arena.

In the present study the type of shelter used was designed to offer no tactical advantage to its owner and to provide no directional bias, so that the value of the shelter was based exclusively on perceptions of the two individuals. Studies based on defensible shelters might find that crayfish are more motivated to occupy those shelters. A tactical advantage resulting from shelter occupancy could be a primary reason for a residency effect in nature.

Only the possibility of a weak residency advantage was found in this study. It seems likely that any residency-effect advantage will usually be overshadowed by significant size difference, but what about the impact of social dynamics? In a stream or 
lake setting, each crayfish probably interacts with numerous individuals on a regular basis. These interactions will occasionally result in contests and provide winners and losers. The relative importance of winner and loser effects relative to residency advantages should be studied in this system.

Residency effects could also play an important role in the establishment of spatial centrality of dominance. Although it has not been demonstrated in this system, a pattern of dominance has been shown to emerge from physical location in other systems. There are two commonly posited reasons for dominant individuals being found in central locations. First, a central position could be the preference of the individual based on some spatial advantage. Alternatively, the spatial dominance structure could simply be the result of the formation of dominance relationships between individuals in the group (see Hemelrijk 2000). This has not been studied in a non-feeding, stationary group. These crayfish are not forming "herds" according to Hamilton's selfish herd. They are entirely restricted by the resource and thus forced to live in close proximity. Because crayfish occupy these shelters, analyzing the spatial data can be made simple by varying the shelter geometry. If shelter occupancy provides an advantage, we should not expect to see the same pattern of dominance. Individuals that would be dominant in the absence of residency effects may be located in suboptimal locations while those that are typically subordinate may be found in better locations because they were there first. This system provides a unique opportunity to investigate the role of dominance in individual location. 


\section{References}

Alcock, J. \& Bailey, W. J. 1997. Success in territorial defense by male tarantula hawk wasps Hemipepsis ustulata: the role of residency. Ecological Entomology 22:377-383.

Arnott, G. \& Elwood, R. W. 2008. Information-gathering and decision-making about resource value in animal contests. Animal Behaviour 76:529-542.

Caballero, C. \& Castro, J. J. 1999. Effect of residence and size asymmetries upon the agonistic interactions between juvenile white-seabream. Aggressive Behavior 25:297-304.

Dugatkin, L. A. 1997. Winner and loser effects and the structure of dominance hierarchies. Behavioral Ecology 8:583-587.

Dugatkin, L. A. \& Reeve, H. K. 1998. Game theory and animal behavior. Oxford University Press. New York, New York.

Dugatkin, L. A. 2001. Bystander effects and the structure of dominance hierarchies. Behavioral Ecology 12:348-352.

Earley, R. L. \& Dugatkin, L. A. 2002. Eavesdropping on visual cues in green swordtail (Xiphophorus helleri) fights: a case for networking. Proc. Royal Soc. London B 1494:943-952.

Edwards, D. D. \& Dimock, R. V. 1991. Relative importance of size versus territorial residency in intraspecific aggression by symbiotic male water mites. Experimental and Applied Acarology 12:61-65.

Enquist, M. \& Leimar, O. 1987. Evolution of fighting behavior: The effect of variation in resource value. Journal of Theoretical Biology 127:187-205.

Evans, D. L. \& Shehadi-Moacdieh, M. 1988. Body size and prior residency in staged encounters between female prawns, Palaemon elegans Rathke. Animal Behaviour 36:452-455.

Fayed, S. A., Jennions, M. D., \& Backwell, P. R. Y. 2008. What factors contribute to an ownership advantage? Biology Letters 4:143-145.

Fero, K., Simon, J. L., Jourdie, V., \& Moore, P. A. 2007. Consequences of social dominance on crayfish resource use. Behaviour 144:61-82.

Figler, M. H., Finkelstein, J. E., Twum, M., \& Peeke, H. V. S. 1995. Intruding male red swamp crayfish, Procambarus clarkii, immediately dominate members of established communities of smaller, mixed-sex conspecifics. Aggressive Behavior 21:225-236.

Garvey, J. E. \& Stein, R. A. 1993. Evaluating how chela size influences the invasion potential of an introduced crayfish (Orconectes rusticus). American Midland Naturalist 129:172-181.

Gherardi, F. \& Atema, J. 2005. Memory of social partners in hermit crab dominance. Ethology 111:271-285.

Gherardi, F. \& Daniels, W. H. 2003. Dominance hierarchies and status recognition in the crayfish Procambarus acutus acutus. Canadian Journal of Zoology 81:12691281.

Gribbin, S. D. \& Thompson, D. J. 1991. The effects of size and residency on territorial disputes and short-term mating success in the damselfly Pyrrhosoma nymphula. Animal Behaviour 41:689-695.

Hack, M. A., Thompson, D. J., \& Fernandes, D. M. 1997. Fighting in males of the autumn spider, Metellina segmentata: Effects of relative body size, prior 
residency and female value on contest outcome and duration. Ethology 103:488498.

Hastings, J. M. 1989. The influence of size, age, and residency status on territory defense in male western cicada killer wasps. Journal of the Kansas Entomological Society 62:363-373.

Hemelrijk, C. K. 2000. Towards an integrative approach to social dominance and spatial structure. Animal Behaviour 59:1035-1048.

Hsu, Y. \& Wolf, L. L. 1999. The winner and loser effect: integrating multiple experiences. Animal Behavior 57:905-910.

Jennions, M. D. \& Backwell, P. R. Y. 1996. Residency and size affect fight duration and outcome in the fiddler crab Uca annulipes. Biol. Journal - Linnean Society 57:293-306.

Koivula, K., Lahti, K., Orell, M., \& Rytkonen, S. 1993. Prior residency as a key determinant of social dominance in the willow tit (Parus montanus). Behavioral Ecology and Sociobiology 33:283-287.

Laimar, O. \& Enquist, M. 1984. Effecys of asymmetries in owner-intruder conflicts. Journal of Theoretical Biology 111:475-491.

Landau, H. G. 1951. On dominance relations and the structure of animal societies. I. Effect of inherent characteristics. Bulletin of Mathematical Biophysics 13:1-19.

Li, H. \& Cooper, R. L. 2001. Spatial familiarity in the blind cave crayfish, Orconectes australis packardi. Crustaceana 74:417-434.

Lodge, D. M., Taylor, C. A., Holdich, D. M., \& Skurdal, J. 2000. Nonindigenous crayfishes threaten North American freshwater biodiversity: lessons from Europe. Fisheries 25:7-20.

Martin, A. L. \& Moore, P. A. 2007. Field observations of agonism in the crayfish, Orconectes rusticus: Shelter use in a natural environment. Ethology 113:11921201.

Maynard Smith, J. 1982. Evolution and the theory of Games. Cambridge University Press, Cambridge.

Morishita, V. R., Buchmannn, F. S., Christofoletti, R. A. Volpato, G. L., \& Barreto, R. E. 2009. Prior residence and body size influence interactions between black sea urchins. Behavioural Processes 80:191-195.

Parker, G. A. 1974. Assessment strategy and the evolution of animal conflicts. Journal of Theoretical Biology 47:223-243.

Pavey, C. R. \& Fielder, D. R. 1996. The influence of size differential on agonistic behaviour in the freshwater crayfish, Cherax cuspidatus. Journal of Zoology 238:445-457.

Prins, R. 1968. Comparative ecology of the crayfishes Orconectes rusticus and Cambarus tenebrosus in Doe Run, Meade County, Kentucky. International Revue Gesamten Hydrobiologie 53:667-714.

Rabeni, C. F. 1985. Resource partitioning by stream-dwelling crayfish: The influence of body size. American Midland Naturalist 113:20-29.

Rosenberg, R. H. \& Enquist, M. 1991. Contest behaviour in Weidemeyer's admiral butterfly Limenitis weidemeyerii (Nymphalidae): the effect of size and residency. Animal Behaviour 42:805-811.

Sale, P. F. 1972. Effect of cover on agonistic behavior of a reef fish: a possible spacing mechanism. Ecology 53:753-758.

Switzer, P. V. 2004. Fighting behavior and prior residency advantage in the territorial dragonfly, Perithemis tenera. Ethology Ecology and Evolution 16:71-89.

Takeuchi, T. 2006. Matter of size or matter of residency experience? Territorial contest in a green hairstreak, Chrysozephyrus smaragdinus. Ethology 112:293-299. 
Taylor, C. A. \& Schuster, G. A. 2004. The Crayfishes of Kentucky. Illinois Natural History Survey Special Publication No. 28.

Turner, G. F. 1994. The fighting tactics of male mouth-brooding cichlids: the effects of size and residency. Animal Behaviour 47:655-662.

Tricarico, E. \& Gherardi, F. 2010. Past ownership makes crayfish more aggressive. Behavioral Ecology and Sociobiology 64:575-581.

Whiting, M. J., Stuart-Fox, D. M., O'Connor, D., Firth, D., Bennett, N. C., \& Blomberg, S. P. 2006. Ultraviolet signals ultra-aggression in a lizard. Animal Behaviour 72:353-363.

Wilson, E.O. 1975. Sociobiology: The new synthesis. Harvard University Press, Cambridge, MA.

Wilson, K. A., Magnuson, J. J., Lodge, D. M., Hill, A. M., Kratz, T. K., Perry, W. L., and Willis, T. V. 2004. A long-term rusty crayfish (Orconectes rusticus) invasion: dispersal patterns and community change in a north temperate lake. Canadian Journal of Fisheries and Aquatic Sciences 61:2255-2266. 
- Born March 20, 1985, Cincinnati, Ohio

- B.S. Biology, Thomas More College, Crestview Hills, KY, 2005

- Nathan M Klar 